\title{
A IMPORTÂNCIA DA GESTÃO DA INFORMAÇÃO PARA A ATUAÇÃO PROFISSIONAL DO SECRETÁRIO EXECUTIVO - UMA REVISÃO DE LITERATURA NACIONAL INTEGRATIVA
}

THE IMPORTANCE OF INFORMATION MANAGEMENT FOR THE PROFESSIONAL PERFORMANCE OF THE EXECUTIVE SECRETARY - AN INTEGRATIVE NATIONAL LITERATURE REVIEW

\section{Nuriane Santos Montezano}

Graduada em Secretariado Executivo Trilíngue pela Universidade Federal de Viçosa, UFV, Brasil. E-mail: nuriane.montezano@embrapa.br

\section{Rosália Beber de Souza}

Doutoranda pela Universidade Federal de Lavras, UFLA, Brasil.

Professora pela Universidade Federal de Viçosa, UFV, Brasil

E-mail: rosaliabeber@posgrad.ufla.br

\section{Odemir Vieira Baeta}

Doutor pela Universidade Federal de Lavras, UFLA, Brasil. Professor pela Universidade Federal de Viçosa, UFV, Brasil

E-mail: odemirbaeta@posgrad.ufla.br 


\title{
A IMPORTÂNCIA DA GESTÃO DA INFORMAÇÃO PARA A ATUAÇÃO PROFISSIONAL DO SECRETÁRIO EXECUTIVO - UMA REVISÃO DE LITERATURA NACIONAL INTEGRATIVA
}

\begin{abstract}
RESUMO
O artigo apresenta a realidade do novo profissional de Secretariado Executivo e sua relação com o Sistema de Informação Estratégico. Todos os conceitos foram trabalhados tendo como base a revisão de literatura nacional integrativa. O objetivo foi o de verificar qual a importância do gerenciamento da informação e sua aplicabilidade ao contexto do profissional de Secretariado Executivo. A discussão e reflexão teórica resultaram que o atual profissional de Secretariado Executivo se encontra preparado para a nova dinâmica organizacional ao incorporar tecnologicamente a execução do gerenciamento de informações em seu contexto. Esta é mais uma atribuição que lhe confere e confirma o seu caráter multifuncional como um dos importantes gestores de informações no processo decisório das organizações.
\end{abstract}

Palavras-chave: Secretariado Executivo; gestão da informação; gestão documental.

\author{
THE IMPORTANCE OF INFORMATION MANAGEMENT FOR THE \\ PROFESSIONAL PERFORMANCE OF THE EXECUTIVE SECRETARY - AN \\ INTEGRATIVE NATIONAL LITERATURE REVIEW.
}

\begin{abstract}
The article presents the reality of the new Executive Secretariat professional and its relation to the Strategic Information System. All the concepts were worked out based on the national integrative literature review. The aim was to determine what is the importance of information management and its applicability to the professional context of the Executive Secretariat. The discussion and theoretical reflection showed that the current Executive Secretary professional is prepared for the new organizational dynamics to incorporate technologically execution management information in context. This is another task that gives and confirms its multifunctional character as an important information manager figure in decision-making organizations.
\end{abstract}

Keywords: Executive Secretariat; information management; document management.

Revista de Gestão e Secretariado - GeSec, São Paulo, v.6, n. 2, p 111-133, maio./agosto 2015 


\section{INTRODUÇÃO}

Os processos que se relacionam com a gestão de informação recebem atenção de forma cada vez mais intensa por parte de governos e grupos econômicos - o que resulta na valorização da informação como recurso. Esse fato pode ser observado pelo seu uso como parâmetro para mensuração de competitividade entre pessoas, grupos, produtos, serviços e atividades.

Contudo, segundo Le Coadic (2004, p.1), "não façamos desse fato, da informação, a chave da inteligibilidade dos processos naturais e do progresso das civilizações, como Duhem fez com a energia no século XIX".

Apesar dessa afirmação, é indiscutível, segundo Braga (2007), o fato de as informações serem equiparadas a outros recursos dentro das empresas, como o capital, por exemplo. Resulta desse fato sua importância estratégica na manutenção da competitividade das empresas, no segmento de mercado em que atuam.

Le Coadic (2004) afirma que a informação possui duas características importantes: sua explosão quantitativa e a implosão do tempo para sua comunicação, e a define como um conhecimento inscrito (registrado) em forma escrita, seja ela em meio impresso ou digital, oral ou audiovisual, em um suporte, possuindo um elemento de sentido, e tendo por objetivo, a transmissão de conhecimento.

Seguindo a premissa de que há um volume cada vez maior de informação, disponibilizada num intervalo de tempo cada vez menor, faz-se necessário gerenciar esse recurso que, apesar de abundante, tende, segundo Marchiori (2002), a ser utilizado de forma ineficiente.

A gestão da informação surge, então, para sanar essa ineficiência, aliando conceitos da gestão estratégica às tecnologias de informação, nas organizações, com o objetivo de sistematizar e organizar o conhecimento, os dados e as informações.

A gestão da informação, de acordo com a descrição de Braga (2007), tem a função de política da empresa, o que possibilita a interação entre as várias "partes” que a constituem, e tem como objetivo apoiar sua política global.

Em suma, trata-se da:

[...] gestão eficaz de todos os recursos de informação relevantes para a organização, tanto a de recursos gerados internamente, como os produzidos externamente e fazendo apelo, sempre que necessário, à tecnologia da informação. (Braga, 2007, p. 3)

Revista de Gestão e Secretariado - GeSec, São Paulo, v. 6, n. 2, p 111-18, maio./agosto. 2015 
Para realizar essa atividade nas empresas, é preciso que haja um profissional capaz de definir as necessidades informacionais, bem como localizar e disseminar informação de qualidade e criar consciência estratégica para a captação desta, priorizando a qualidade, verificando sua exatidão, utilidade e aplicabilidade e personalizando sua forma de apresentação, tornando-a mais atraente. (Marchiori, 2002).

Como ressaltado por Medeiros e Hernandes (2004), a profissão de Secretário Executivo passou por uma evolução, assim como ocorreu com diversas outras profissões, e essas transformações trouxeram novas competências, dentre elas: visão generalista da organização e das peculiares relações hierárquicas e intersetoriais; capacidade de lidar com modelos inovadores de gestão; capacidade de maximização e otimização de recursos tecnológicos.

Esses autores afirmam, também, que tal profissional é responsável por assessorar o executivo, transmitindo-lhe informações, dominando suas atividades, sem supervisão direta, e com iniciativa para tomar decisões, segundo os objetivos assinalados pela autoridade.

A partir desta constatação, questiona-se: qual a importância da gestão da informação para a atual atuação do profissional de Secretariado Executivo?

Justificamos este estudo pela necessidade de articular mais explicitamente as relações profissionais do Secretariado Executivo com a melhor aplicabilidade do gerenciamento da informação no seu contexto de trabalho. Dessa forma, pretendemos identificar pela revisão de literatura integrativa como o tema da gestão da informação tem sido abordado e verificar quais as atuais atribuições dos profissionais do Secretariado Executivo apresentadas pela literatura técnica e acadêmica. Apresentaremos quais atividades desse profissional se relacionam com a gestão da informação, e a importância desta atividade, em particular, para a atuação do Secretário Executivo nas empresas.

De modo geral, este artigo tem o objetivo de conceituar e demonstrar a importância da gestão da informação para a rotina de trabalho do Secretário Executivo, dentre outras atribuições a ele conferidas. Em termos específicos, busca-se: verificar se as atividades requeridas ao profissional que lida com informação convergem com as atividades exercidas pelo Secretário Executivo; examinar a importância da informação para a competitividade das empresas, no contexto atual e averiguar se ele tem condições de atuar como gestor da informação. Após esta introdução, o artigo está estruturado em sessões metodológicas, teóricas e de considerações, a segunda sessão está 
subdividida em subseções que articulam a temática desde a definição e a gestão da informação, o profissional desta área, a realidade do profissional de Secretariado Executivo e a discussão do Secretário Executivo como gestor da informação e, posteriormente as considerações finais.

\section{PROCEDIMENTOS METODOLÓGICOS}

O trabalho de pesquisa bibliográfica primária desenvolvida foi conduzido pari pasu seguindo o modelo da revisão de literatura integrativa, tendo como base a literatura nacional que aborda as referidas temáticas. Conforme recomendação de Botelho, Cunha e Macedo (2011), optamos por esta metodologia de revisão por possibilitar a sistematização, organização e síntese da visão do estado da arte nos estudos em secretariado executivo e gestão da informação.

O objetivo desta etapa é verificar nas principais produções nacionais, as possibilidades para contribuir com a expansão do campo de estudos em Secretariado Executivo. Todo o processo de pesquisa exige rigor metodológico e sistematização; contudo, nas pesquisas qualitativas faz necessário para auxiliar na sua validação, de modo que, não somente os resultados, mas todo o processo de condução da pesquisa possa ser generalizado. Esperamos com o detalhamento desta etapa, contribuir para o indispensável rigor nos procedimentos de pesquisa.

Assim para as pesquisas desenvolvidas nas ciências sociais aplicadas, especificamente, nos estudos secretariais, este exercício metodológico auxilia na identificação de que corroborar na discussão teórica ou possíveis contradições que poderão ser trabalhadas posteriormente. Partindo dessa possibilidade, adotaremos uma revisão integrativa da literatura nacional mapeando as referências bibliográficas legitimadas pela sua inserção e uso nos cursos de Secretariado Executivo no país.

Para proceder a sistematização, buscamos um método em particular que possa nos evidenciar as produções científicas legitimadas pela comunidade acadêmica e científica nacional que tenham contribuído teórico-metodológico e empiricamente no campo dos estudos em secretariado executivo. Por conseguinte, Galvão, Sawada e Trevizan (2008) afirmam que este trabalho permite verificar e analisar o status quo do conhecimento em determinada área, pois possibilita acessar o que vem sendo trabalhado ao longo de um determinado período. 


\section{REFERENCIAL TEÓRICO}

\subsection{A INFORMAÇÃO}

A definição de informação é apresentada por diversos autores, porém a conceituação de Le Coadic (2004) demonstra, com clareza, suas principais características. Para o autor, a informação é um conhecimento inscrito (registrado) em forma escrita, seja ela em meio impresso ou digital, oral ou audiovisual, em um suporte; possui um elemento de sentido e tem por objetivo a transmissão de conhecimento.

Sendo assim, McGee e Prusak (1994) defendem que a informação não é formada apenas por dados coletados, mas sim por dados coletados, organizados, ordenados e submetidos a um determinado contexto, para que, dessa forma, possuam significado. Logo, para que dados se transformem em informação, eles devem ser estruturados, interpretados e inseridos num contexto específico por seu usuário.

Contextualizando historicamente, Siqueira (2005) apresenta o seguinte quadro comparativo da evolução do conceito de informação e de sua importância:

Quadro 1. Contexto histórico sobre informação

\begin{tabular}{|l|l|l|}
\hline Período & Conceito de informação & Importância \\
\hline Anos de 1950 & $\begin{array}{l}\text { Requisito burocrático } \\
\text { necessário }\end{array}$ & Redução do custo de processamento de muitos papéis \\
\hline $\begin{array}{l}\text { Anos de 1960 e } \\
1970\end{array}$ & $\begin{array}{l}\text { Suporte aos propósitos gerais } \\
\text { organização }\end{array}$ \\
\hline $\begin{array}{l}\text { Anos de 1970 e } \\
1980\end{array}$ & $\begin{array}{l}\text { Controle do gerenciamento da daversas tarefas da } \\
\text { organização }\end{array}$ & Auxiliar e acelerar os processos de tomada de decisão \\
\hline Anos de 1990 & Vantagem competitiva & Garantir a sobrevivência e prosperidade da organização \\
\hline
\end{tabular}

Fonte: Adaptado de Siqueira (2005).

A informação assume, atualmente, um espaço cada vez maior em qualquer setor da atividade humana. Segundo Neiva e D'Elia (2005), esse crescimento da informação, decorrente dos avanços tecnológicos e de sua transmissão e armazenamento, afeta o universo empresarial, o que aumenta 
proporcionalmente a importância de saber lidar com essa ferramenta, também considerada geradora de dividendos e lucros.

A informação, de acordo com Bukland (1991 apud Oleto, 2006), possui três usos principais: 1) informação como processo, que muda o conhecimento de alguém e pode ser considerada o ato de informar um objeto, um documento, um dado ou um evento e está vinculada ao nível de conhecimento de quem recebe a informação, num determinado momento; 2) informação como conhecimento, que diminui as incertezas, referindo-se a fatos, assuntos ou eventos; e 3) informação como coisa, que trata de informativos em suas características físicas, ou seja, dados e documentos.

Devido ao impacto que a informação pode acarretar em seus usuários, é necessário que se estabeleça um padrão de qualidade para ela, com a finalidade de avaliar e verificar qual a melhor forma de as empresas a utilizarem. É preciso cautela ao utilizar a informação, visto que nem todas são verídicas e/ou provêm de fontes confiáveis.

Segundo Oleto (2006), quem lida com informação deve selecionar, dentre tantas, aquelas que têm qualidade. Le Coadic (2004) afirma que o futuro da informação será marcado por sua explosão quantitativa e pela implosão do tempo para sua comunicação, ou seja, haverá uma quantidade cada vez maior de informação disponível em um intervalo de tempo cada vez mais curto.

Sendo assim, Oleto (2006, p.60) apresenta parâmetros de qualidade da informação, com base em dois focos: 1) a abordagem da qualidade da informação baseada no produto, que lida com a informação como coisa e atribui a ela características como "abrangência, acessibilidade, atualidade, confiabilidade, objetividade, precisão e validade"; e 2) a abordagem da qualidade da informação baseada no usuário, que busca atender às necessidades de uso da informação, verificadas por meio de pesquisas, dentre as quais se encontram a adequação da indexação e classificação das informações, a eficiência na recuperação destas, sua eficácia, impacto, relevância e utilidade.

Portanto, para que se gerencie e se verifique a qualidade de uma quantidade cada vez maior de informação, disponibilizada em intervalos de tempo cada vez menores, Braga (2007) aponta que as empresas percebem a necessidade de obter recursos melhores do que os de seus concorrentes, e de aperfeiçoar a utilização da informação, uma vez que, de acordo com McGee e Prusak (1994, p. 3), "a concorrência entre as organizações baseia-se em sua capacidade de adquirir, tratar, interpretar e utilizar a informação de forma eficaz". 
Nesse contexto, a informação transforma-se em recurso estratégico para as empresas, permitindo-lhes competir, obter os resultados desejados e sobreviver à concorrência.

Como observado por Siqueira (2005), a informação representa, atualmente, uma importante ferramenta no processo de tomada de decisões, uma vez que sua análise permite à empresa perceber oportunidades e ameaças a sua operação, e a detecção de problemas e tendências.

McGee e Prusak (1994, p. 4) afirmam que "a informação é capaz de criar valor significativo para as organizações, possibilitando a criação de novos produtos e serviços e aperfeiçoando a qualidade do processo decisório".

Assim, a informação serve de base para tomadas de decisões estratégicas pelas empresas. De acordo com Rascão (2006), as decisões estratégicas são adotadas pelos gestores e precedem toda e qualquer ação, independente do processo organizacional pelo qual foram tomadas.

Essas decisões estratégicas envolvem aspectos relacionados tanto com o ambiente interno quanto com o externo, ou seja, abrangem a escolha do produto e, ou serviço que as organizações poderão disponibilizar aos seus clientes, buscando, assim, desenvolver e aproveitar, da melhor forma possível, os recursos existentes, a fim de atingir seus objetivos.

A informação permite ampliar o leque de possibilidades na elaboração de estratégias e criar oportunidades para o desenvolvimento de novas atividades, por parte da organização. Para isso, segundo McGee e Prusak (1994), a informação deve ser tratada da mesma forma que outros recursos, como capital, mão de obra e tecnologia.

A informação pode ser abordada como um diferencial estratégico de uma empresa quando, conforme afirma Siqueira (2005), assume as seguintes características: Informação como vantagem competitiva - quando a empresa gera informações estratégicas, com base em ferramentas mais desenvolvidas do que as de outras organizações; produtos de informação - oportunidades geradas a partir da criação ou remodelagem da informação, agregando-lhe valor e criando vantagem competitiva; e comercialização de informações - utilização da capacidade excedente como produto comercial.

Nessa mesma linha, McGee e Prusak (1994) mostram que, para definição da estratégia, deve-se coletar informação válida e abrangente sobre o ambiente externo e sobre o estado atual da organização. Para isso, deve-se definir como a empresa se distinguirá das demais; orientar, especificamente, escolhas importantes a serem tomadas, considerando sempre o ambiente externo; e 
considerar todos os recursos que a firma deverá reunir e que serão necessários à implementação da estratégia.

Para Siqueira (2005), o ambiente estratégico da informação está demonstrado no quadro a seguir:

Quadro 2. - Estratégia da informação

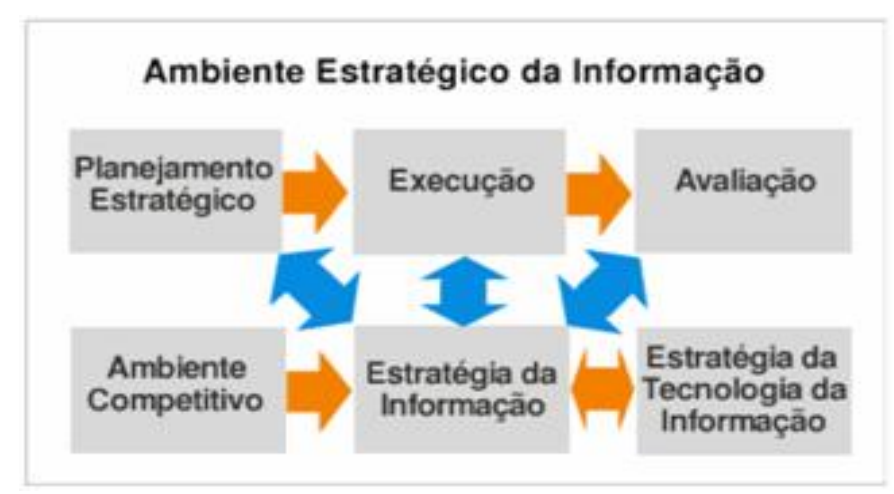

Fonte: Adaptado de Siqueira (2005).

As tecnologias da informação, de acordo com Braga (2007), conduzem a inovações e aumentam, assim, a riqueza das organizações, atraindo novos investimentos e permitindo, então, uma melhoria nos produtos e serviços oferecidos aos clientes.

De acordo com Le Coadic (2004, p. 90), Tecnologia da Informação (TI) são "todas as técnicas eletrônicas de informação que possuem em comum o fato de emitir, receber, veicular e armazenar ou processar sinais elétricos".

A utilização dessas tecnologias tem um rendimento maior quando associada aos Sistemas de Informação (SI), que são definidos por Palmisano e Rosini (2003, p. 3) "como um conjunto de elementos interdependentes em interação, visando atingir um objetivo comum”.

Seguindo esse raciocínio, os autores dizem que um sistema de informação estratégico tem como principal característica a capacidade de proporcionar subsídios para modificações nos objetivos, nas operações, nos produtos, nos serviços e até nas relações dentro da empresa, podendo, inclusive, mudar ou direcionar o foco dos negócios.

A partir dessa premissa, Braga (2007, p. 5) estabelece a seguinte relação entre as tecnologias da informação e o sistema de informação: 
Ao nível dos SI, são definidas as necessidades de informação e sua aplicação no negócio, baseadas numa análise da organização e do seu meio envolvente, bem como na análise da estratégia global da organização. Ao nível das TI, é estabelecido qual a sua contribuição para o processamento de informação e para a satisfação das necessidades informacionais e aplicacionais, bem como o desenvolvimento de sistemas e criação de vantagens competitivas para a empresa, tendo em conta as prioridades fixadas na estratégia dos SI.

Assim, deve-se sempre levar em consideração, no momento de formular a estratégia, quais os caminhos que uma empresa seguirá para manter-se competitiva, a relação entre as tecnologias e os sistemas de informação. Além disso, é preciso avaliar o conteúdo informacional e certificar-se da confiabilidade das fontes que alimentam esses sistemas de informação.

\subsection{A GESTÃO DA INFORMAÇÃO}

As organizações, para atingirem seus objetivos e tendo como foco tanto seus clientes como seus colaboradores, devem ter uma gestão eficiente, o que, segundo o Manual de Gestão dos Serviços de Informação (Marchiori, 2002, p. 74), "é um conjunto de processos que englobam atividades de planejamento, organização, direção, distribuição e controle de recursos, visando à racionalização e à efetividade de determinado sistema, produto ou serviço". Dessa forma, gestão da informação é um conjunto de processos que envolvem atividades de planejamento, organização, direção, distribuição e controle de informações, tendo como objetivo a racionalização e a efetividade de determinado sistema, produto ou serviço.

Marchiori (2002, p.74) diz, ainda, que a gestão da informação visa "incrementar a competitividade empresarial e os processos de modernização organizacional”. Já na visão de Braga (2007), o objetivo da gestão da informação é apoiar a política global da empresa, tornando o conhecimento e a articulação entre as várias "partes" que a constituem mais eficientes.

Ainda segundo Braga (2007), a empresa, ao atuar num mundo global, está em estado permanente de "necessidade de informação", uma vez que a informação constitui o suporte de uma organização e é um elemento essencial e indispensável à sua existência. Ele afirma que uma empresa não funciona sem informação, porém é importante saber utilizar esse recurso.

Marchiori (2002) defende que qualquer processo que tenha como foco o acesso a uma informação de qualidade depende da estruturação e da coordenação de um conjunto de dados, 
colocados à disposição e oferecidos como produto e, ou serviço para os clientes de uma organização, sejam eles internos ou externos.

A gestão da informação também se faz importante no processo de tomada de decisão, que requer do executivo conhecimento prévio das condições internas da organização e do ambiente externo desta para avaliar as melhores medidas a serem tomadas.

McGee e Prusak (1994) descrevem tarefas que devem ser realizadas para o desenvolvimento de um processo de gerenciamento de informação eficiente.

O primeiro passo a ser seguido é a identificação de necessidades e requisitos de informação, que é classificada como a etapa mais importante de todo o processo, e que busca atender aos seguintes aspectos: a variedade necessária, pois o número de fontes que alimentam um sistema precisa ser tão variado quanto o ambiente interpretado; deve-se considerar, também, que as pessoas não sabem o que não sabem, ou seja, elas têm dificuldade de identificar sua carência quanto à informação; e a aquisição/coleta de informações, que demonstra a necessidade de haver um plano sistemático para adquirir a informação de sua fonte de origem ou coletá-la daqueles que a desenvolvem internamente.

O segundo aspecto a ser trabalhado no processo de gerenciamento da informação, segundo McGee e Prusak (1994), é definido em duas etapas: classificação e armazenamento de informação/tratamento e apresentação de informação. Apesar de, com frequência, ocorrerem simultaneamente, precisam ser planejadas como tarefas independentes. A classificação e o armazenamento determinam de que forma os usuários terão acesso e utilizarão as informações necessárias para o desenvolvimento de suas atividades e, ainda, selecionam a melhor forma de armazená-las. Segundo os autores, as muitas considerações técnicas dificultam o aprofundamento das explanações dessa etapa do processo. Contudo, eles afirmam que as informações fornecidas são suficientes para a compreensão dessa fase.

A terceira etapa das tarefas apresentadas por McGee e Prusak (1994) é o desenvolvimento de produtos e serviços de informação - quando os usuários finais do sistema têm a possibilidade de usufruir do seu próprio conhecimento e experiência para trazer contribuições relevantes ao processo. 


\subsection{O PROFISSIONAL DA INFORMAÇÃO}

A inserção de uma vasta gama de aparatos tecnológicos, oriundas da chamada Sociedade da Informação, deu margem ao surgimento de uma nova terminologia para designar ou categorizar aqueles que lidam com informação, conhecidos por "profissionais da informação" (Mota \& Oliveira, 2005).

Além disso, segundo Marchiori (2002), o excesso de dados e de informação acessíveis e a necessidade de um gerenciamento eficaz de tais recursos informacionais garantiram aos profissionais que lidam com informação, cada vez mais, importância dentro das empresas.

Cabe ao profissional da informação o desenvolvimento das atividades de processamento de dados, a fim de torná-los fontes de informação. De acordo com Mota e Oliveira (2005, p. 99), os profissionais da informação são aqueles que "adquirem informação registrada em qualquer suporte, organizam, descrevem, indexam, armazenam, recuperam e distribuem essa informação em sua forma original ou como produtos elaborados a partir dela".

Para Ponjuan e Danta (2000 apud Mota e Oliveira, 2005, p.100), os profissionais que lidam diretamente com informação devem operar eficiente e eficazmente tudo o que se refere ao gerenciamento da informação, em organizações de qualquer tipo ou em unidades especializadas de informação.

Mota e Oliveira (2005) afirmam que esses profissionais são responsáveis por coordenar equipes de funcionários e desenvolver e dirigir programas e sistemas que atendam às necessidades informacionais dos usuários. Tais usuários podem ser tanto clientes internos da empresa, que utilizarão os sistemas de informação em suas atividades, como clientes externos, utilizando o produto informacional elaborado por esses profissionais para os fins que desejarem, de acordo com a solicitação feita pelos clientes.

Para lidar com informação, o profissional, segundo Marchiori (2002), deve interpretar, analisar e sintetizar os conteúdos dos dados coletados de maneira cuidadosa, tanto os provenientes de ambientes internos, quanto externos à empresa, e colocados à disposição dela. Além disso, deve implementar uma estratégia de acompanhamento de resultados oriundos da implantação do sistema de informação criado, para que o desempenho desse sistema seja avaliado.

Outra atribuição do profissional da informação, de acordo com Siqueira (2005), é a capacidade de sintetizar e avaliar experiências cruas e, a partir delas, criar modelos que representem 
as abstrações das experiências, para dar suporte às ações futuras pela identificação e utilização dessas informações.

Enfim, deve ter capacidade de gerar soluções diferenciadas para clientes singulares, "aproveitando racionalmente um recurso que, embora abundante 'em espécie', tende a ter gargalos para sua utilização eficiente". (Marchiori, 2002, p.79). Ainda segundo o autor, os profissionais que lidam diretamente com informação buscam corresponder às exigências dinâmicas da sociedade e contribuir para que os recursos informacionais sejam cada vez mais rentáveis e eficazes na tomada de decisões.

Para isso, devem gerenciar informação pensando e planejando estrategicamente, estruturando articulações políticas e analisando mercados e contextos, para que tenham condições de satisfazer as necessidades informacionais de seus clientes. Para desenvolver essas habilidades, exige-se, do profissional que lida com informação, alto nível de mobilidade pessoal e profissional, atuando seja como consultor, seja como assessor. Ele deve estar ciente de que sua competência está diretamente ligada ao seu grau de atualização, capacidade de empreendimento e criatividade.

Aliás, "a criatividade e a percepção de parâmetros de tempo e valor, associados à informação de que o cliente necessita, são os requisitos básicos para o oferecimento de serviços e produtos" (Marchiori, 2002, p.78).

Em síntese, o gestor da informação, conforme defende Marchiori (2002), deve desempenhar as seguintes atividades:

auxiliar na definição das atividades desenvolvidas pelo usuário e na explicitação de suas necessidades de informação;

localizar e disseminar as informações de qualidade e criar uma estratégia para a captação de informações importantes e de interesse do usuário;

priorizar a informação relevante para o usuário e a qualidade dessa informação, observando características como exatidão, utilidade e aplicabilidade, entre outras;

personalizar a forma de apresentação e disseminação da informação;

utilizar-se de metodologias para o desenvolvimento de sistemas de informação e ferramentas de apresentação dessas informações;

desenvolver um pensamento crítico e analítico para perceber e entender os problemas de informação e comunicação, conforme as perspectivas técnicas, organizacionais e pessoais; 
administrar a tecnologia de informação, analisando, de forma crítica, seu custo, qualidade e complexidade.

\subsection{O PROFISSIONAL DE SECRETARIADO EXECUTIVO}

Neiva e D’Elia (2005) afirmam que a profissão de Secretariado Executivo não só acompanhou a evolução gradativa da história, como criou a sua própria, tanto por meio da mudança do perfil profissional e das competências a ele atribuídas, quanto no nível de responsabilidades adquiridas.

Essas mudanças foram decorrentes das transformações que aconteceram em diversos setores, como, por exemplo, na economia e na política, e esse profissional passou a se destacar nas empresas, já que estas buscam profissionais que acompanham e antecipam tendências.

Neiva e D’Elia (2005) afirmam que o profissional de Secretariado é de inquestionável importância para organizações, por trabalhar ao lado do poder decisório, otimizando resultados em equipes, projetos e nas múltiplas opções que o mercado oferece.

As autoras complementam afirmando que tal profissional passou "a gerenciar as questões rotineiras e a assessorar os executivos, recebendo, para isso, maior soma de poderes decisórios" (Neiva \& D’Elia, 2005, p. 21).

Medeiros e Hernandes (2004, p. 312) definem o profissional de Secretariado Executivo, de acordo com as mudanças ocorridas com o passar dos anos, da seguinte maneira:

[...] profissional que assessora o executivo, transmite-lhe informações e executa as tarefas que lhe são confiadas. Ela transformou-se, no mundo moderno dos negócios e nessa era de globalização da economia, em assistente executiva que domina as habilidades sem supervisão direta e tem iniciativa para tomar decisão segundo os objetivos assinalados pela autoridade.

Descrevendo, ainda, o perfil desse profissional, Neiva e D'Elia (2005) dizem que ele deve atuar de forma qualitativa; estar inserido nos processos gerenciais das empresas, atuando como elo entre parceiros, fornecedores e clientes; gerenciando informações e administrando processos.

Essas características, que moldam o novo perfil traçado para o Secretário Executivo, exigem que ele entenda que a organização é composta de vários processos interligados. 
Sendo assim, dentre as diversas funções atribuídas aos Secretários Executivos, de acordo com Neves (2007), destaca-se a sua atuação estratégica nas empresas, uma vez que passa a ser sua responsabilidade justificar as medidas e ações da organização, ou seja, eles passam a atuar como mediadores das ações da empresa, como demonstrado no quadro a seguir:

\section{Quadro 3: Evolução da rotina de trabalho}

\begin{tabular}{|l|l|}
\hline Antes & Agora \\
\hline Envio e recebimento de correspondências & $\begin{array}{l}\text { Coordenação e trâmite de papéis no departamento } \\
\text { e de assuntos de rotina }\end{array}$ \\
\hline Abastecimento do setor com material de trabalho & $\begin{array}{l}\text { Coordenação de compras cotação com } \\
\text { fornecedores, administração dos custos da área. }\end{array}$ \\
\hline Atendimento de ligações telefônicas & Atendimento ao cliente \\
\hline Manutenção de arquivos físicos & Manutenção de arquivos eletrônicos \\
\hline Execução de tarefas operacionais & Gerenciamento de tarefas operacionais \\
\hline
\end{tabular}

Fonte: Adaptado de Neves (2007).

Ainda de acordo com Neves (2007), o profissional de Secretariado Executivo tem a possibilidade de ver a organização como um todo, tem acesso a todas as informações e pode formar opinião crítica do problema e sinalizar as soluções. Segundo Neiva e D’Elia (2005), esse profissional é responsável pela dinâmica operacional, que reflete diretamente no desempenho das empresas.

A formação profissional de Secretariado Executivo deve, segundo Carvalho (2005), contemplar as relações entre o conhecimento teórico e as exigências da prática cotidiana da profissão. Para tanto, os profissionais devem estar preparados para assessorar executivos, gerenciar setores e pessoas, gerir fluxo de informação e utilizar novas tecnologias em um cenário de mudanças culturais, econômicas, políticas, sociais e profissionais.

Como profissionais que figuram ao lado do poder decisório, devem saber gerenciar todo o fluxo de informação da sua área de atuação, segundo Neiva e D’Elia (2005, p. 47):

A velocidade exigida no mundo dos negócios, aliada à complexidade gerada pelo volume e pela variedade de informações, faz com que a importância do gerenciamento da informação assuma um papel vital nas organizações e, principalmente, na atividade da Secretária. 
As autoras concluem afirmando a importância do Secretariado Executivo na organização do sistema de informação da empresa, devido às suas habilidades e competências técnicas. Dentre as atividades exercidas por eles, encontram-se, ainda, a elaboração de documentos e relatórios, como descrito já na primeira Lei de $\mathrm{n}^{\circ} 7.377$, de 30 de setembro de $1985^{1}$, que regulamentou a profissão.

Essas competências estão diretamente relacionadas à gestão da informação e incluem, ainda, o gerenciamento de diversos tipos de documentos empresariais.

Ainda segundo a lei que rege a profissão, nota-se, dentre as atribuições do Secretário Executivo, a gestão da informação, como disposto no art. $4^{\circ}$, que elenca as seguintes habilidades: "III - coleta de informações para a consecução de objetivos e metas da empresa; V - interpretação e sintetização de textos e documentos".

A gestão documental, uma das atribuições do Secretário Executivo, está vinculada à gestão da informação e, por vezes, pode ser entendida como parte integrante desta.

Considera-se gestão de documentos, de acordo com o artigo $3^{\circ}$ da Lei Federal $n^{\circ} 8.159$, de 8 de janeiro $1991^{2}$, “o conjunto de procedimentos e operações técnicas à sua produção, tramitação, uso, avaliação e arquivamento em fase corrente e intermediária, visando sua eliminação ou recolhimento para guarda permanente".

As formas atuais de produzir, transferir e usar informações estão cada vez mais associadas a padrões tecnológicos, o que se traduz em alterações significativas nos conceitos e nas práticas das empresas, nos métodos de trabalho e nos parâmetros de produtividade (Rondinelli, 2002).

Seguindo a teoria de Rondinelli (2002), em ambientes empresariais que utilizam a tecnologia de forma cada vez mais intensa, os documentos em meio eletrônico necessitam de novas formas de gerenciamento, uma vez que demandam peculiaridades, especificidades jurídicas e tecnológicas para garantir sua utilização e conservação. Porém, Rodrigues (2005) salienta que, sob o ponto de vista conceitual, os documentos em meio eletrônico têm as mesmas características dos documentos tradicionais.

Seguindo esses princípios de modernização e de adequação à sociedade e às novas tecnologias, verifica-se a utilização de uma nova ferramenta na manutenção e utilização de arquivos

\footnotetext{
${ }^{1}$ Brasil. Lei $\mathrm{n}^{\mathrm{o}}$ 7.377, de 30 de setembro de 1985. Dispõe sobre o Exercício da Profissão de Secretário, e dá outras Providências. Recuperado em 15 agosto, 2012, de http://www.trt02.gov.br/geral/tribunal2/Legis/CLT/Profis_regul/L7377_85.html.

${ }^{2}$ Brasil. Lei no 8.159, de 8 de janeiro de 1991. Dispõe sobre a Política Nacional de Arquivos Públicos e Privados, e dá outras Providencias. Recuperado em 2 dezembro, 2012, de

$<$ http://www6.senado.gov.br/legislacao/ListaPublicacoes.action?id=134588.
} 
eletrônicos, bem como no gerenciamento dos documentos em suporte digital: o Gerenciamento Eletrônico de Documentos - GED.

Segundo Neiva e D'Elia (2005), o GED tem como papel gerenciar, eletronicamente, todo o caminho, reduzindo o manuseio do documento original, em suporte material, proporcionando uma economia de espaço físico e de tempo. Esse é um instrumento que possibilita grande automação aos profissionais que utilizam os documentos eletrônicos e as informações neles contidas, uma vez que eles podem ser impressos, enviados por fax, e-mail e até mesmo serem editados.

As autoras afirmam que, para o processo de Gerenciamento Eletrônico de Documentos, devem-se selecionar equipamentos adequados, tais como scanners, discos e outros hardwares, além de aplicações adequadas, pois “converter documentos em imagens eletrônicas vai além da escolha da tecnologia ou do preço da compra de um equipamento novo" (Neiva e D’Elia, 2005, p. 49).

Medeiros e Hernandes (2004, p. 232) alertam para o aspecto legal. Segundo os autores, a "legislação brasileira determina a guarda de originais por tempo determinado ou mesmo indefinidamente". Portanto, transferir um documento do suporte material para o imaterial demanda tanto cautela quanto estudo prévio dos aspectos legais e de custo/benefício.

\subsection{O PROFISSIONAL DE SECRETARIADO EXECUTIVO COMO GESTOR DE INFORMAÇÃO}

O novo século inicia-se sob uma proposta de ampla conectividade, de preocupação com os conteúdos criados, manipulados e disseminados para públicos heterogêneos, e determinação de competências profissionais - organizacionais e, ou individuais - que sejam responsáveis pelos processos e atividades de uma sociedade voltada para a informação e para o aprendizado (Marchiori, 2002).

Segundo Le Coadic (2004), a mudança do suporte material para o imaterial fez com que as informações se multiplicassem quase que infinitamente, de modo que agora se gerenciam fluxos ininterruptos e profusos de informações.

Contudo, apesar de abundante, nem toda informação disponível é fidedigna e considerada de qualidade, segundo os critérios apresentados por Oleto (2006): abrangência, acessibilidade, atualidade, confiabilidade, objetividade, precisão e validade, caso considere-se o produto de 
informação; ou, caso o usuário seja considerado como parâmetro para medir a qualidade, a adequação à necessidade de informação do mesmo.

Com base nessa afirmação e, observando as referências bibliográficas compiladas, verificou-se que a informação surge como uma das principais ferramentas no desenvolvimento das atividades de uma empresa.

A informação passa a ser considerada como um recurso estratégico e, a partir dessa nova visão, verifica-se a necessidade de gerenciá-la.

As atividades inerentes à gestão da informação, segundo Marchiori (2002), podem ser consideradas como um conjunto de processos que englobam atividades de planejamento, organização, direção, distribuição e controle da informação, a fim de utilizá-la da maneira mais apropriada e de acordo com as políticas e preceitos de cada organização.

A gestão da informação é vista como o gerenciamento de todos os recursos informacionais relevantes para o desenvolvimento empresarial.

Atualmente, essa atividade requer um profissional capacitado para executar uma função que está cada vez mais abrangente, pois, apesar de o uso da informática tornar os serviços mais rápidos e eficientes, e de os sistemas serem cada vez mais complexos, não há operação, nem realização de nenhuma atividade de forma autônoma, sem a interação humano-computador (Marchiori, 2002).

Os profissionais que trabalhavam com informação eram, há algum tempo, em sua maioria, apenas arquivistas, bibliotecários e alguns profissionais na área da informática.

De acordo com Mota e Oliveira (2005, p. 99), hoje "não há ainda unanimidade em torno de uma denominação comum para abarcar as diferentes habilidades que se vinculam às atividades de informação".

Como profissionais da informação, Le Coadic (2004) entende que são aqueles capazes de adquirir informação registrada em qualquer suporte; organizá-la; descrevê-la; indexá-la; armazenála; recuperá-la e distribuí-la, tanto em sua forma original como em produtos elaborados a partir dela.

Além disso, esses profissionais têm uma vasta possibilidade de atuação no mercado, como afirmam Mota e Oliveira (2005, p. 106), na indústria e negócios: no atendimento a empresários executivos, que necessitam de informações precisas, que os mantenham em nível de competição com outras empresas. Estes podem ser considerados como clientes típicos e variam desde proprietários de empresas de pequeno porte a diretores das grandes companhias, firmas de seguro e 
de investimento, agências de publicidade e relações públicas, indústrias de manufatura e serviço; nos bancos e finanças: na recuperação e análise de informações estratégicas e competitivas determinantes para transações comerciais e financeiras de sucesso; poder público: em diversas instâncias, que vão desde a atuação em universidades e centros de pesquisa até arquivos públicos e gestão de bancos de dados, que incluem documentos orçamentários, pesquisa sobre distribuição de renda, qualidade de vida da população, dentre outros; ciência e tecnologia: no fornecimento de informações para o embasamento e a consolidação de pesquisas de profissionais de todas as áreas do conhecimento, atendendo desde pesquisadores de Ciências Exatas até os de Ciências Humanas.

É necessário, atualmente, que o profissional que lida com informação seja capaz de analisar, sistematizar e até mesmo tomar decisões baseadas em informações e, dentre esses profissionais, destaca-se o profissional de Secretariado Executivo.

De acordo com Neiva e D'Elia (2005), o dinamismo exigido no meio empresarial, aliado à complexidade e ao grande volume e variedade de informações, faz com que a importância do gerenciamento dessas assuma um papel vital nas organizações e, principalmente, na atividade do Secretariado Executivo.

Medeiros e Hernandes (2006) apontam algumas tarefas relacionadas à gestão da informação para os Secretários Executivos, dentre as quais se destacam a captação de informações que se relacionem com a empresa; o estabelecimento de critérios de seleção das informações, de modo que estas sejam objetivas e atendam às necessidades de seus usuários; e manutenção de um sistema prático e atualizado de armazenamento de informações, tanto para uso pessoal, quanto para o auxílio de outros profissionais.

Como consequência da estreita relação estabelecida entre o profissional de Secretariado Executivo e os executivos, esses profissionais participam do processo de tomada de decisões ativamente, uma vez que são responsáveis pela triagem e organização de documentos e, até mesmo, pela compilação de informações e pela elaboração de relatórios e de apresentações que darão embasamento a essas decisões.

Considerando que uma das vertentes da gestão da informação é a gestão documental, cabe ao profissional de Secretariado Executivo, dentro de suas competências, a organização e o desenvolvimento de arquivos que possibilitem a utilização de documentos, uma vez que as funções do arquivo, de acordo com Neiva e D’Elia (2005, p.174), se resumem na preservação da documentação, tornando-a útil como informação, e têm como principais objetivos recolher, 
selecionar, classificar e catalogar os documentos; conservar e garantir o caráter confidencial dos dados sob sua custódia, além de proporcionar a consulta de forma rápida e a pronta localização dos documentos.

Gerenciar arquivos eletrônicos também faz parte das atribuições inerentes ao cargo de Secretário Executivo e, segundo Azevedo e Costa (2002), os trabalhos de arquivamento de documentos eletrônicos devem seguir os mesmos preceitos dos arquivos tradicionais, permitindo fácil acesso às informações e atendendo às exigências da empresa.

Quando são comparadas as atribuições do profissional de Secretariado com as dos chamados "profissionais da informação", verificam-se muitas similaridades entre elas.

Por exemplo, quando Marchiori (2002) afirma que o profissional da informação deve localizar e disseminar as informações de qualidade, percebe-se, também, essa tarefa entre as atribuições de um Secretário Executivo.

As semelhanças são ainda mais evidentes quando se verifica que o profissional da informação deve, de acordo com Marchiori (2002), priorizar a informação relevante para o usuário e verificar a qualidade dessa informação, observando características como a exatidão, a utilidade e a aplicabilidade, entre outras; também nessa atividade verifica-se uma equivalência com as atribuições requeridas ao Secretariado Executivo.

Assim como outras: personalizar a forma de apresentação e disseminação da informação - o Secretário Executivo elabora relatórios, apresentações e documentos comerciais, modificando a forma como se visualiza a informação inicial, e por meio de sua intervenção, torna a apresentação das informações mais objetiva, segundo os propósitos aos quais devem servir; desenvolver um pensamento crítico e analítico para perceber e entender os problemas de informação e comunicação, conforme as perspectivas técnicas, organizacionais e pessoais - o Secretário deve filtrar o grande volume de informação destinada aos executivos, de forma crítica, analisando seu conteúdo e verificando a qualidade das informações. Assim, aos gestores somente serão encaminhadas as informações que fazem parte de suas necessidades, permitindo a eles tomarem decisões que tragam resultados positivos para a organização. 


\section{CONSIDERAÇÕES FINAIS}

Ao retomar ao objetivo da discussão proposta neste trabalho buscamos verificar a importância da gestão da informação para a atuação profissional do Secretário Executivo diante da nova realidade profissional. A partir das discussões obtidas com a revisão integrativa da literatura sobre a gestão da informação e sobre o profissional de Secretariado Executivo, foi possível verificar que a informação é um importante instrumento de trabalho, também, para esse profissional. Primeiramente, verificamos a importância e a valorização dada a informação por parte das organizações. Alguns autores, inclusive, equipararam o recurso informação ao capital.

A grande valorização da informação fez com que as empresas investissem cada vez mais na gestão desse recurso, considerando-o uma ferramenta estratégica para se manterem competitivas, num ambiente cada vez mais volátil e complexo. Todos, de funcionários a grandes corporações, tiveram de aprender a gerenciar um volume crescente de informações e selecionar, dentre tantas, quais realmente eram dotadas de valor estratégico e correspondiam às suas necessidades. A informação impactou, sobremaneira, no mercado de trabalho. Assim como nas empresas, esse recurso modificou as atribuições de diversos profissionais, inclusive as referentes ao profissional de Secretariado Executivo.

Qualquer que seja o processo dentro de uma empresa, este somente será viabilizado se sustentado por informações fidedignas. Para isso, é preciso que haja profissionais capazes de filtrar, estruturar, interpretar e fornecer informações. Por atuar próximo aos executivos das empresas, o Secretário Executivo trabalha diretamente com eles, assessorando-os em tarefas como planejamento, redação de relatórios e produção de apresentações, por exemplo.

Essa proximidade possibilita ao profissional atuar como uma ponte entre clientes internos tanto os que pertencem ao mesmo departamento, como os que pertencem a outros setores -, externos à empresa, como clientes e fornecedores, e os executivos que eles assessoram.

A gestão da informação pode ser observada como uma atribuição do Secretário Executivo, se observada a contribuição da aplicação dos conceitos da ciência da informação e da documentação, e da observância dos ciclos da informação e dos documentos dentro das organizações. A gestão documental, que, por sua vez, está diretamente ligada ao profissional de Secretariado Executivo, visto que cabe a ele a função de elaborar, receber, verificar, ordenar, classificar e definir a finalidade de diversos documentos, é uma das muitas ferramentas utilizadas 
por esse profissional para gerenciar informação. Segundo a consulta bibliográfica realizada, informação nada mais é do que dados estruturados e acessíveis, quando necessários. Portanto, pelo domínio das técnicas relativas a arquivamento e gestão de documentos, por responsabilizar-se pela filtragem da documentação e das correspondências, por elaborar relatórios e apresentações, por atuar próximo aos gestores e junto com eles, assessorando-os e possuindo conhecimento dos negócios em que estão envolvidos, o profissional de Secretariado atua de fato como um gestor de informações nas mais diversas organizações.

Como sugestão para pesquisas futuras, recomendamos um estudo aplicado empiricamente à nova realidade profissional do Secretário Executivo e sua relação com a gestão da informação. Cabe ainda, indicar a possibilidade de estudos que contemplem a produção internacional da área de Secretariado Executivo e sua articulação com a temática do gerenciamento da informação para cada vez mais subsidiar os estudos secretariais. Assim, muito se poderia agregar, gerar novas discussões e contribuir para a expansão do conhecimento da área secretarial.

\section{REFERÊNCIAS}

Azevedo, Ivanize; Costa, Sylvia Ignácio da (2002). Secretária: um guia prático. São Paulo: SENAC.

Botelho, L. L. R; Cunha, C. C. A \& Macedo, M. (2011). O método da revisão integrativa nos estudos organizacionais. Gestão e Sociedade. Belo Horizonte, vol.5, n.11, pp.121-136, maio/agosto.

Braga, Ascenção (2007). A gestão da informação. Recuperado em 7 março, de 2009< http://www.arquivar.com.br/espaco_profissional/sala_leitura/artigos/Gestao_da_Informacao.pdf $>$.

Carvalho, Miréia Maria Joau de (2005). Qual será o futuro dos cursos de Secretariado Executivo? Revista Acadêmica de Secretariado Executivo. Salvador, vol. 1, n. 1.

Galvão, C. M.; Sawada, N. O. \& Trevizan, M. A. (2008). Revisão sistemática: recurso que proporciona a incorporação das evidências na prática da enfermagem. Revista Latino-Americana de Enfermagem, Ribeirão Preto, vol. 12, n. 3, pp. 549-556, maio/junho.

Neiva, Edméa Garcia \& D’Elia, Elizabete Silva (2005). Secretária executiva. (1a ed.). São Paulo: IOB-Thomson.

Le Coadic, Yves-François (2004). A ciência da informação (2a ed.). Maria Yêda F. S. de Filgueiras Gomes, Trad.). Brasília: Briquet de Lemos, Tradução: 
Marchiori, Patricia Zeni (2002). A ciência da gestão de informação: compatibilidades no espaço profissional. Recuperado em 10 março de 2009, Disponível em: < http://www.scielo.br/pdf/ci/v31n2/12910.pdf $>$.

Mcgee, James \& Prusak, Laurence (1994). Gerenciamento estratégico da informação - aumente a competitividade e a eficiência da sua empresa utilizando a informação como uma ferramenta estratégica (17a ed.). Rio de Janeiro: Elsevier.

Medeiros, João Bosco \& Hernandes, Sonia (2004). Manual da secretária (9a ed.). São Paulo: Atlas.

Mota, Francisca Rosaline Leite \& Oliveira, Marlene (2005). Formação e atuação profissional. In: Oliveira, Marlene de. Ciência da informação e biblioteconomia: novos conteúdos e espaços de atuação. Belo Horizonte: UFMG.

Neves, Maria da Conceição de Oliveira. (2007). Introdução ao secretariado executivo. Rio de Janeiro.

Oleto, Ronaldo Ronan (2006). Percepção da qualidade da informação. Recuperado em 5 março, 2012. de <http://www.scielo.br/pdf/ci/v35n1/v35n1a07.pdf $>$.

Palmisano, Ângelo \& Rosini, Alessandro Marco (2003). Administração de sistemas de informação e gestão do conhecimento. São Paulo: Thomson.

Rascão, José Poças (2006). Da gestão estratégica da informação: como aumentar o tempo disponível para a tomada de decisão estratégica. Rio de Janeiro, e-papers.

Rondinelli, Rosely Cury. (2002). Gerenciamento arquivístico de documentos eletrônicos. Rio de Janeiro: Editora FGV.

Rodrigues, Ana Marcia Lutterbach. (2005). A teoria dos arquivos e a gestão de documentos. Recuperado em 5 março, 2012. de < http://www.scielo.br/pdf/pci/v11n1/v11n1a09.pdf .

Siqueira, Marcelo Costa (2005). Gestão estratégica da informação (1a ed.) Rio de Janeiro: Brasport. 